\title{
Female copulatory tubes and the subdivision of the genus Anthocoris (Heteroptera: Anthocoridae: Anthocorini)
}

\author{
YunLING KE and WenJun BU* \\ Institute of Entomology, College of Life Sciences, Nankai University, Tianjin 300071, China; e-mail: wenjunbu@nankai.edu.cn
}

Key words. Heteroptera, Anthocoridae, Anthocoris, copulatory tube, species group

\begin{abstract}
We report a systematic study of the female copulatory tubes of forty species in the genus Anthocoris, most of which are from the Northern Hemisphere. Our results indicate that female copulatory tubes can be used as a reliable character to identify females and analyze phylogenetic relationships in this genus. We propose thirteen species groups based on the copulatory tubes of females, other morphological characters of both sexes, and the previous species groups adopted in the continental faunas.
\end{abstract}

\section{INTRODUCTION}

The genus Anthocoris Fallén is the second largest genus in the family Anthocoridae of the suborder Heteroptera, which includes about seventy species (Gross, 1954; Henry \& Froeschner, 1988; Péricart, 1996; Carpintero, 2002). As the taxonomy of Anthocoris is mostly based on the males, it is hard to identify female specimens to species in some cases, especially in closely related species, due to their similarity in the appearance.

The female copulatory tube in the family Anthocoridae is a secondary copulatory structure that exists in the tribes Anthocorini, Blaptostethini, Oriini and Scolopini. The entrance of this specialized structure is on the surface of the abdominal intersegmental membrane between sterna VII and VIII, very close to the valvulae (Carayon, 1957).

Carayon (1953) studied the copulatory tube of Anthocoridae first and suggested that this special structure might play a role in the temporary storage of sperm. Since then, a number of studies have demonstrated the differences in number, position, and structure of the copulatory tubes in several genera and some species in the family Anthocoridae (Carayon, 1956, 1957, 1961, 1972; Péricart, 1972; Muraleedharan \& Ananthakrishnan, 1978; Yasunaga, 1997, 2000; Hernández \& Stonedahl, 1999; Bu \& Zheng, 2001; Postle et al., 2001; Ke \& Bu, 2005). Recently, the copulatory tube was reported to be stable within species, suggesting the feasibility of using this structure as an important character for identifying females in some genera, such as Orius Wolff, Acompocoris Reuter and Tetraphleps Fieber, and to infer the phylogenetic relationship of the Anthocoridae.

The present study, presents detailed examination of the copulatory tubes of forty species in the genus Anthocoris.

\section{MATERIAL AND METHODS}

\section{Material}

Some of the specimens examined are deposited in the Institute of Entomology, Nankai University (NKUM); others were on loan from four institutions, whose names are listed in acknowledgements.

\section{Method for preparing copulatory tubes}

Relax the specimen with a relaxing reagent (Ethanol $100 \mathrm{ml}$, distilled water $75 \mathrm{ml}$, Benzene $10 \mathrm{ml}$, Ethyl acetate $10 \mathrm{ml}$ ) for 3-5 min. Separate the abdomen from the thorax with a dissecting needle, place the abdomen into $1 \% \mathrm{KOH}$ and heat it with boiling water for 20-30 $\mathrm{min}$ (the duration of heating may be adjusted according to the freshness of specimens, the hardness of the body wall etc.) to dissolve muscles and other tissues in the abdomen. Dye the abdomen with a solution of Chlorazol black for a few minutes; rinse with clean water once or twice; tear terga I to VII along the suture between terga and sterna with forceps and a dissecting needle; remove sterna II to VII leaving the intersegmental membrane between sterna VII and VIII. Keep the intersegmental membrane connected to sternum VIII to obtain a complete copulatory tube along with the genital segment. After drawing, the genital segment with the copulatory tube and other parts of the body should be preserved in a vial containing glycerin and the original label attached.

\section{RESULTS}

The copulatory tube of Anthocoris can be divided into two parts, a basal duct and an apical sac (Fig. 1). The duct is usually tubular and attached to the upper or lower surface, or the folded edge of abdominal intersegmental membrane (Fig. 2) between sterna VII and VIII, extending forwards to abdominal segment IV or III. The sac usually resembles a sphere or an ellipsoid and connects to the apical part of the duct.

Careful examination of forty species of Anthocoris, revealed distinct differences between the copulatory tubes of different species of Anthocoris in the following characters: the site where the duct joins the bulb, the length, texture and diameter of different parts, the number and degree of twist, and other special structures near the place where the duct and the sac are connected. The size and shape of the sac is not constant, even in same species, and can be altered during the preparation process. This reduces the taxonomical importance of the sac, so this

\footnotetext{
* Author for correspondence.
} 

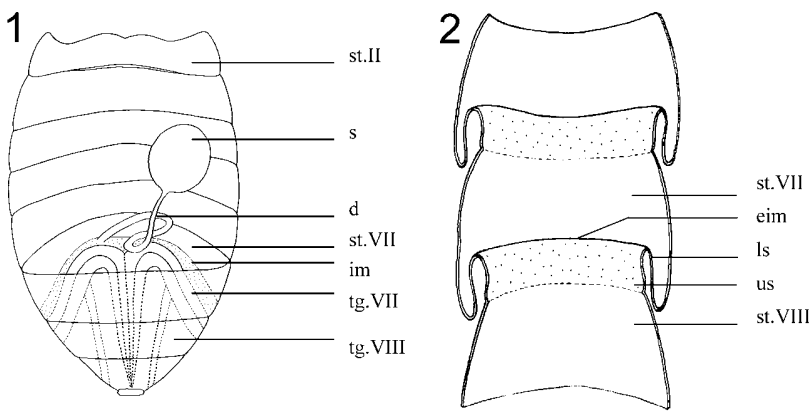

Figs 1-2. 1 - the abdomen of Anthocoris in dorsal view (terga I-VI were removed, demonstrating the position and the general structure of female copulatory tubes). st.II - sternum II; s - sac; $\mathrm{d}$ - duct; st.VII - sternum VII; im - intersegmental membrane between sterna VII and VIII; tg.VII - tergum VII; tg.VIII tergum VIII. 2 - sterna VI-VIII and their intersegmental membranes in dorsal view. st.VII - sternum VII; eim - edge of intersegmental membrane between sterna VII and VIII; ls - lower surface; us - upper surface; st.VIII - sternum VIII.

character is not described in the following text. Based on the examination of forty species, we divide the copulatory tubes into ten types, described below.

\section{A. albiger type}

Duct very long, coiled; attached to extreme right of lower surface of intersegmental membrane between sterna VII and VIII; diameter of basal 3/4 slightly variable; a short section apparently thickened at apical $1 / 4$, then thinned abruptly, sclerotized and reaching the sac; a relatively long apical section enters into the sac.

\section{A. albiger (Fig. 3)}

Duct length $1.9 \mathrm{~mm}$; the thickening at apical $1 / 4$ very short, twice as wide as basal $3 / 4$; apical $1 / 8$ of the whole duct entered into the sac, forms a U-turn and thickens gradually to sub-apex, then thinned abruptly at apex.

\section{A. whitei (Fig. 4)}

Duct length $2.5 \mathrm{~mm}$; thickened section at apical 1/4 longer than that of $A$. albiger, more than twice diameter of basal 3/4; apical 1/12 enters into the sac, forms an arch, diameter of apical 1/12 hardly varies.

\section{A. alpinus type}

Duct usually with a few twists with many transverse rugosities on the wall; attached to extreme left of intersegmental membrane between sterna VII and VIII; basal section never dilated; apical section sclerotized and enters into the sac.

\section{A. alpinus (Fig. 5)}

Duct length $0.5 \mathrm{~mm}$; attached to lower surface of intersegmental membrane; rugosities fine and dense; the whole duct thins gradually from base to apex.

\section{A. kerzhneri (Fig. 6)}

Duct thick; length $0.9 \mathrm{~mm}$; attached to lower surface of intersegmental membrane; diameter of the whole duct nearly constant; wall of basal half slightly thin, with fine rugosities; wall of following $1 / 3$ thickened, without rugosity; apical 1/6 sclerotized, nearly half of the sclerotized part enters into the sac.
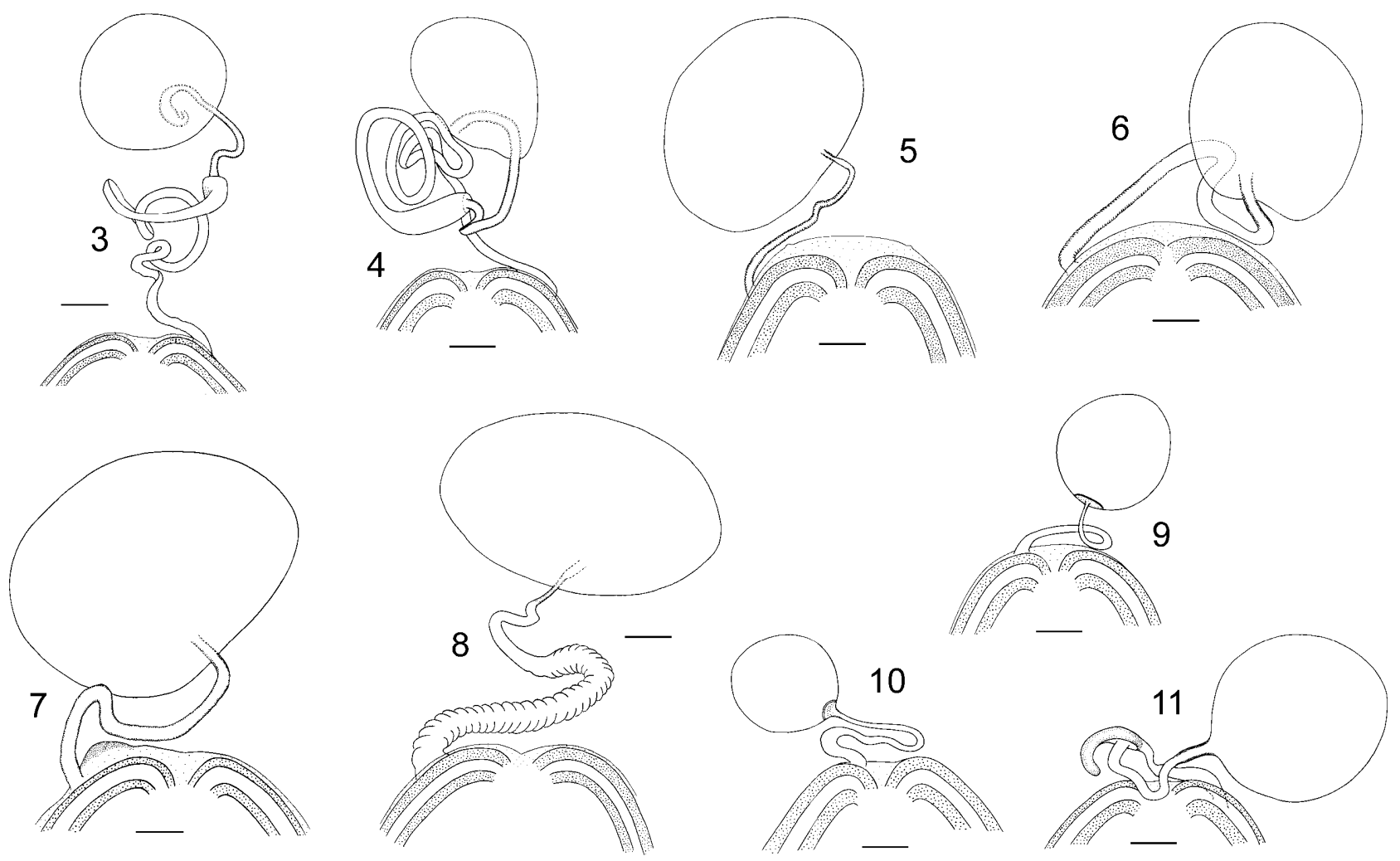

Figs 3-11: Copulatory tubes of Anthocoris spp. 3-A. albiger; 4 -A. whitei; 5 -A. alpinus; 6 - A. kerzhneri; 7 - A. qinlingensis; 8 -A. zoui; 9 - A. chibi; $10-$ A. notatotibialis; $11-$ A. fulvipennis. Scale $=0.1 \mathrm{~mm}$. 


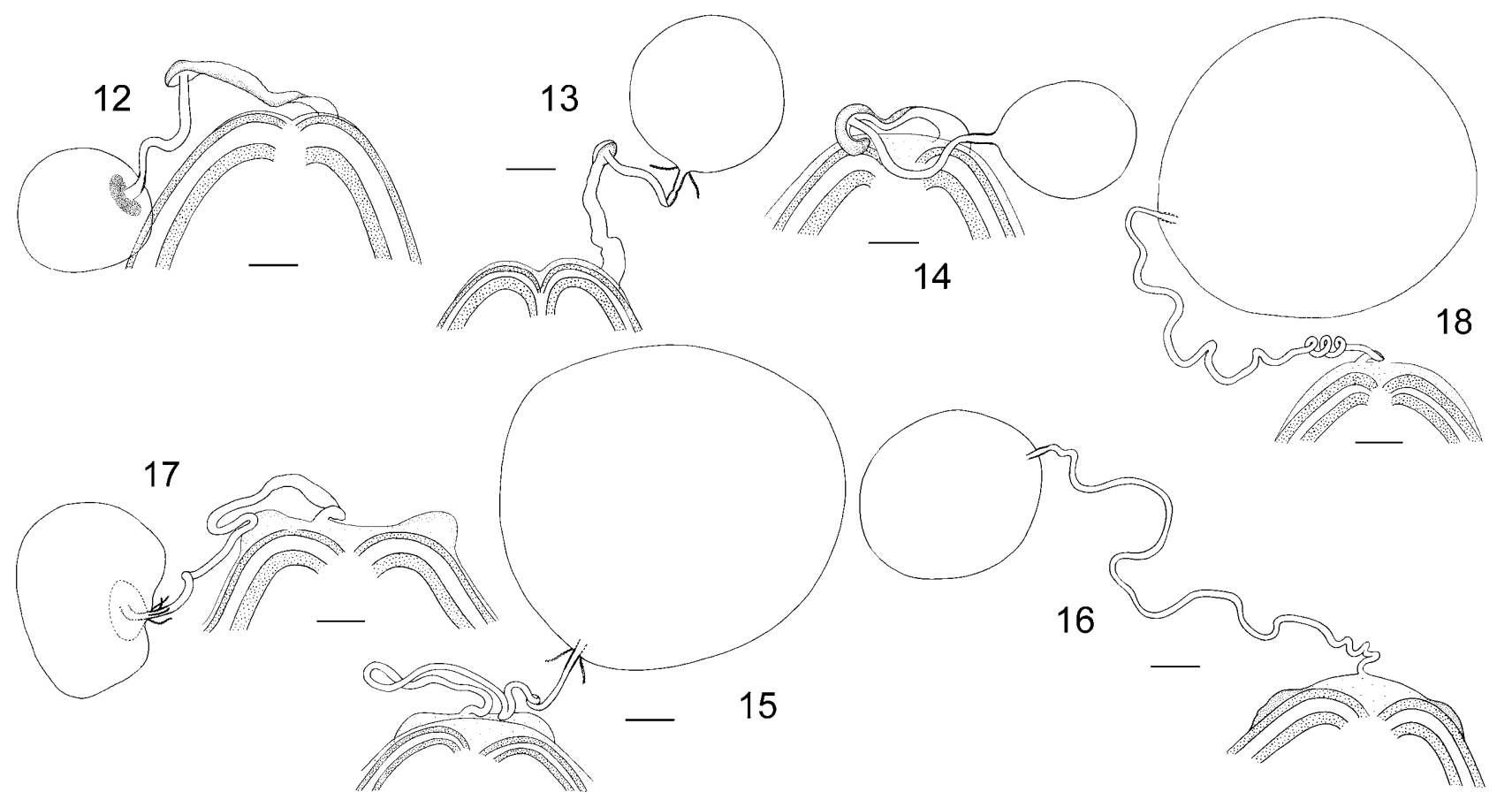

Figs 12-18: Copulatory tubes of Anthocoris spp. 12 - A. nigripes; 13 - A. rufotinctus; $14-$ A. variipes; $15-$ A. bakeri; $16-$ A. confusus; $17-$ A. gallarumulmi; $18-A$. japonicus. Scale $=0.1 \mathrm{~mm}$.

\section{A. qinlingensis (Fig. 7)}

Intersegmental membrane between sterna VII and VIII with a thick apophysis on the left edge. Duct thick; length $0.7 \mathrm{~mm}$; attached to upper surface of intersegmental membrane, left to the apophysis; the whole duct thins gradually from base to apex, rugosities fine; apical $1 / 8$ sclerotized, most of the sclerotized section enters into the sac.

\section{A. zoui (Fig. 8)}

Duct length $1.1 \mathrm{~mm}$; attached to lower surface of intersegmental membrane; basal 3/5 very thick with rough rugosities; apical 2/5 thinned, smooth without rugosity; subapical section connected with the sac sclerotized, thinnest; apical 1/10 enters into the sac.

\section{A. chibi type}

Duct short, attached to the left upper surface of intersegmental membrane between sterna VII and VIII; apical part sclerotized slightly. Sac with strongly sclerotized annular structure encircling the junction of duct and sac; the wall of sac within the annular structure thickened.

\section{A. chibi (Fig. 9)}

Duct length $0.4 \mathrm{~mm}$; base to subapex thins gradually; apical ending thickened slightly.

\section{A. notatotibialis (Fig. 10)}

Duct length $0.6 \mathrm{~mm}$; with a few twists; basal $1 / 4$ much thicker than the rest; sub-basal to subapical part thins gradually; apex thickened.

The copulatory tubes are very similar between these two species, but they are different in the degree of twists, the variation in diameter and the length of the duct.

\section{A. fulvipennis type}

Duct attached to the right or extreme right of lower surface of intersegmental membrane between sterna VII and VIII. Duct divided clearly into two segments, basal half and apical half. Basal half thick and compressed, more or less transformed into a spoon-like structure, the wall of spoon handle thin and the wall of spoon bowl thick; apical half extended from the middle of the spoon bowl, tubular, with thick wall, usually thinner than basal half.

\section{A. fulvipennis (Fig. 11)}

Duct length $0.8 \mathrm{~mm}$; attached to extreme right lower surface of intersegmental membrane; basal half of spoon handle thick, narrowing near spoon bowl, spoon bowl relatively long and strongly curved; apical half thins gradually towards the subapical section, apical $1 / 4$ thickened slightly and sclerotized.

\section{A. nigripes (Fig. 12)}

Duct length $0.7 \mathrm{~mm}$; attached to right lower surface of intersegmental membrane; basal half of spoon handle thick, spoon bowl relatively short and small; apical half thins gradually towards the subapical section, apical part thickened and sclerotized. The wall of sac thickened around the junction with the duct.

\section{A. rufotinctus (Fig. 13)}

Duct length $0.6 \mathrm{~mm}$; attached to extreme right lower surface of intersegmental membrane; basal half of spoon handle thins gradually to spoon bowl, spoon bowl small; diameter of apical half nearly same, apical $1 / 3$ sclerotized; the middle of the sclerotized part thinned slightly. Sac with a pair of short tubules near the junction of duct and sac. 

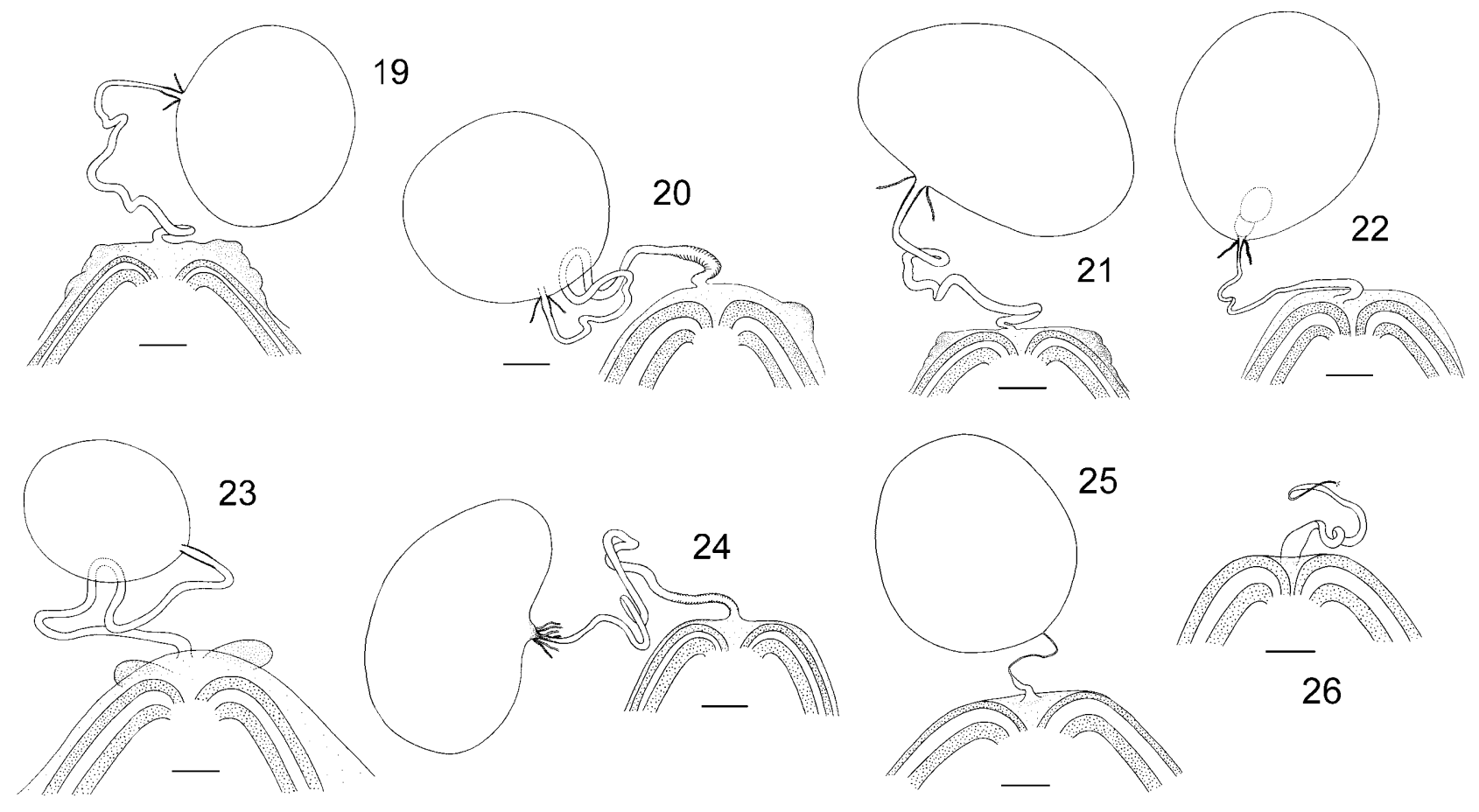

Figs 19-26: Copulatory tubes of Anthocoris spp. 19 - A. minki; 20 - A. sarothamni; 21 - A. simulans; 22 - A. takahashii; 23 - A. ussuriensis; $24-$ A. visci; $25-$ A. dividens; $26-$ A. miyamotoi. Scale $=0.1 \mathrm{~mm}$.

\section{A. variipes (Fig. 14)}

Duct length $0.8 \mathrm{~mm}$; attached to right lower surface of intersegmental membrane; spoon handle of basal half thinned gradually to spoon bowl, spoon bowl long and strongly curved; diameter of apical half nearly same, apical part thickened slightly and sclerotized.

\section{A. gallarumulmi type}

Intersegmental membrane between sterna VII and VIII often with some thick apophyses. Duct usually long, with a lot of twists, attached near the middle edge of intersegmental membrane; diameter of the whole duct varied little in most species; apical part sclerotized, often slightly entering the sac. Two, four or six wire-like short tubules with rough outer surfaces often on the sac, very close to the apex of the duct; their apices opening into the abdominal cavity; function uncertain.

\section{A. bakeri (Fig. 15)}

Lower surface of intersegmental membrane expanded extensively, forming a flat apophysis. Duct thin, length $1.2 \mathrm{~mm}$; attached to the place near the middle edge of the apophysis; basal section slightly sclerotized, turned to the right, then bent to the left. Sac with two tubules near the junction of duct and sac.

\section{A. confusus (Fig. 16)}

Intersegmental membrane with an apophysis at each side. Duct thin; length $1.5 \mathrm{~mm}$; attached to the middle of intersegmental membrane.

\section{A. gallarumulmi (Fig. 17)}

Intersegmental membrane with an arched apophysis at each side. Duct length $0.9 \mathrm{~mm}$; attached to left edge of intersegmental membrane, then turned to the right; thickened at basal 1/7, two times as thick as the rest of duct. Sac with an elliptical vesicle within enclosing apical section of duct; four tubules surrounding subapical section of duct symmetrically.

\section{A. japonicus (Fig. 18)}

Duct thin; length $1.4 \mathrm{~mm}$; attached to left edge of intersegmental membrane; basal part turned to the right, then bent left; apical section slightly thickened.

\section{A. minki (Fig. 19)}

Apophysis at each side of intersegmental membrane with a rough edge. Duct length $0.9 \mathrm{~mm}$; attached to the middle of intersegmental membrane; basal part bent to the right horizontally, then turned to the left; the whole duct except apical part narrows gradually to apex; apical part thickened slightly. Sac with two tubules near the junction of duct and sac.

\section{A. sarothamni (Fig. 20)}

Intersegmental membrane with arched apophysis on extreme right margin. Duct length $1.2 \mathrm{~mm}$; attached near the middle edge of intersegmental membrane; basal 1/7 thick, with some transverse rugosities; rest relatively thin, without rugosity. Sac with two tubules near the junction of duct and sac.

\section{A. simulans (Fig. 21)}

Apophysis at each side of intersegmental membrane with a rough edge. Duct length $0.9 \mathrm{~mm}$; attached to the middle of intersegmental membrane, basal part thinner than the rest, slants towards the left, then bent to the right. Sac with two tubules near the junction of duct and sac. 


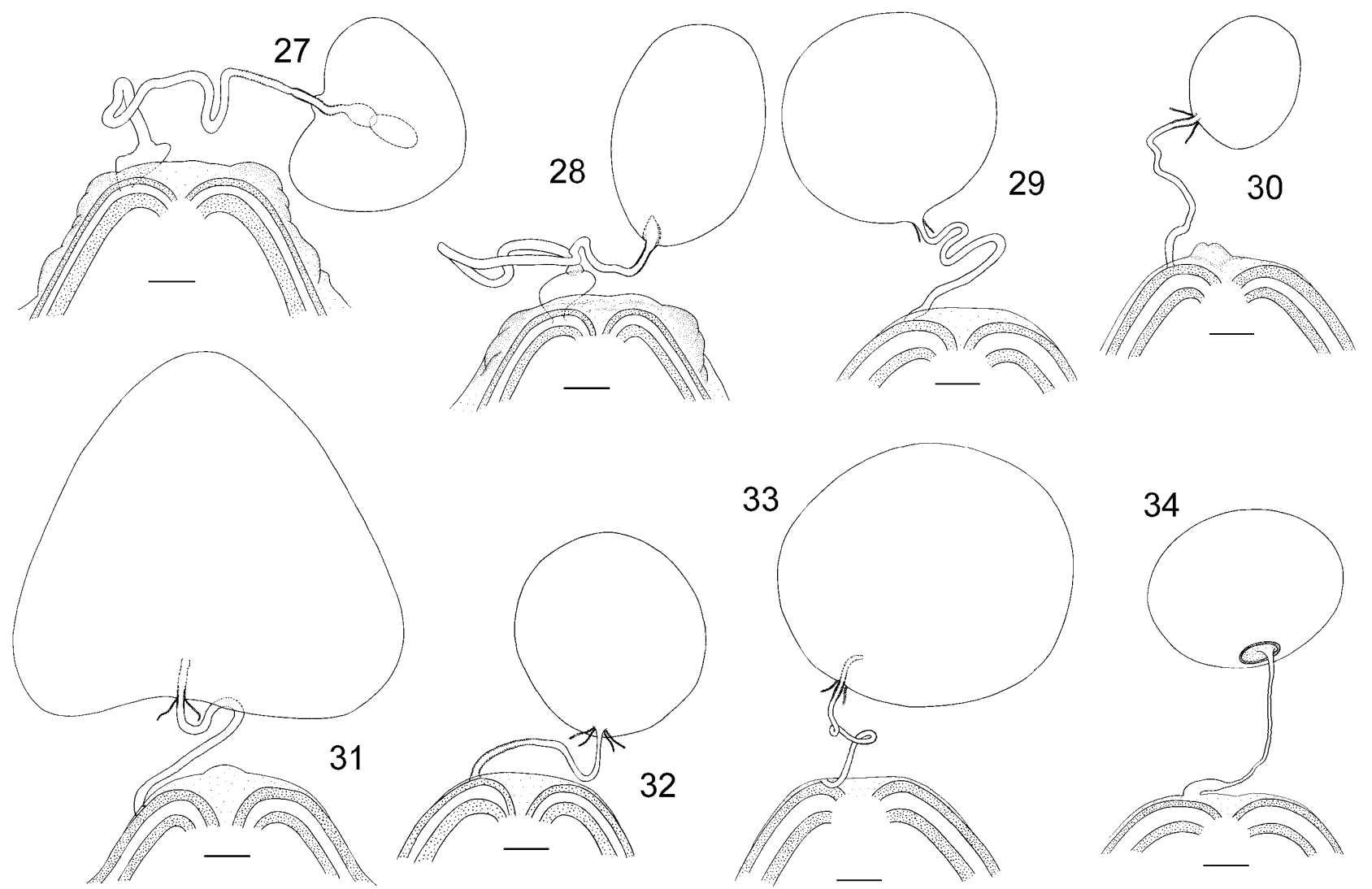

Figs 27-34: Copulatory tubes of Anthocoris spp. 27 - A. butleri; 28 - A. nemoralis; 29 - A. antevolens; 30 - A. limbatus; 31 - A. montanus; $32-$ A. musculus; $33-$ A. nemorum; $34-$ A. pilosus. Scale $=0.1 \mathrm{~mm}$.

The copulatory tubes are very similar in $A$. minki and $A$. simulans, but they are different in the diameter of basal section of the duct, and how they bend in the basal and sub-basal parts of the duct.

\section{A. takahashii (Fig. 22)}

Duct length $0.6 \mathrm{~mm}$; attached to left of upper surface of intersegmental membrane, extended rightwards, then bends to the left; basal $1 / 3$ much thicker than rest, rest very thin; apical part thickened slightly, connected with a gourd-shaped vesicle in the sac. Sac with two tubules near the junction of duct and sac.

\section{A. ussuriensis (Fig. 23)}

Intersegmental membrane with an apophysis at each side of lower surface. Duct length $1.2 \mathrm{~mm}$; attached to the middle of intersegmental membrane, basal and apical parts slightly thicker than rest.

\section{A. visci (Fig. 24)}

Duct length $1.2 \mathrm{~mm}$; attached to the middle of intersegmental membrane, thinned gradually to apex; basal part with many rough transverse rugosities; rest relatively smooth with a few fine rugosities. Sac with the wall around where it connects with the duct thickened and bulged; on the bulge, six tubules encircled the junction of duct and sac.

\section{A. miyamotoi type}

Duct attached to middle of intersegmental membrane between sterna VII and VIII; apical part of duct or the whole duct except basal part extremely thin, wire-like, smooth and sclerotized.

\section{A. dividens (Fig. 25)}

Duct length $0.3 \mathrm{~mm}$; attached to middle of upper surface of intersegmental membrane; with a few twists; basal $1 / 3$ relatively thick; apical $2 / 3$ wire-like.

\section{A. miyamotoi (Fig. 26)}

Duct length $0.7 \mathrm{~mm}$; attached to middle of lower surface of intersegmental membrane; lot of twists; diameter of whole duct varied markedly; basal $1 / 5$ thick; middle $3 / 5$ thinned, about $2 / 5$ as thick as basal part; apical $1 / 5$ wire-like. Sac connected to wire-like section of duct.

Although we dissected as many specimens of $A$. miyamoto $i$ as we could, no trace of the sac at the end of duct was seen. The sac probably broke off during the dissections.

\section{A. nemoralis type}

Intersegmental membrane between sterna VII and VIII with thick, rough-edged apophyses at both sides. Whole duct long; attached to left of lower surface of intersegmental membrane; lot of twists; basal part dilated, cystiform; rest thins gradually subapically; apical section sclerotized, partially entering into the sac. 


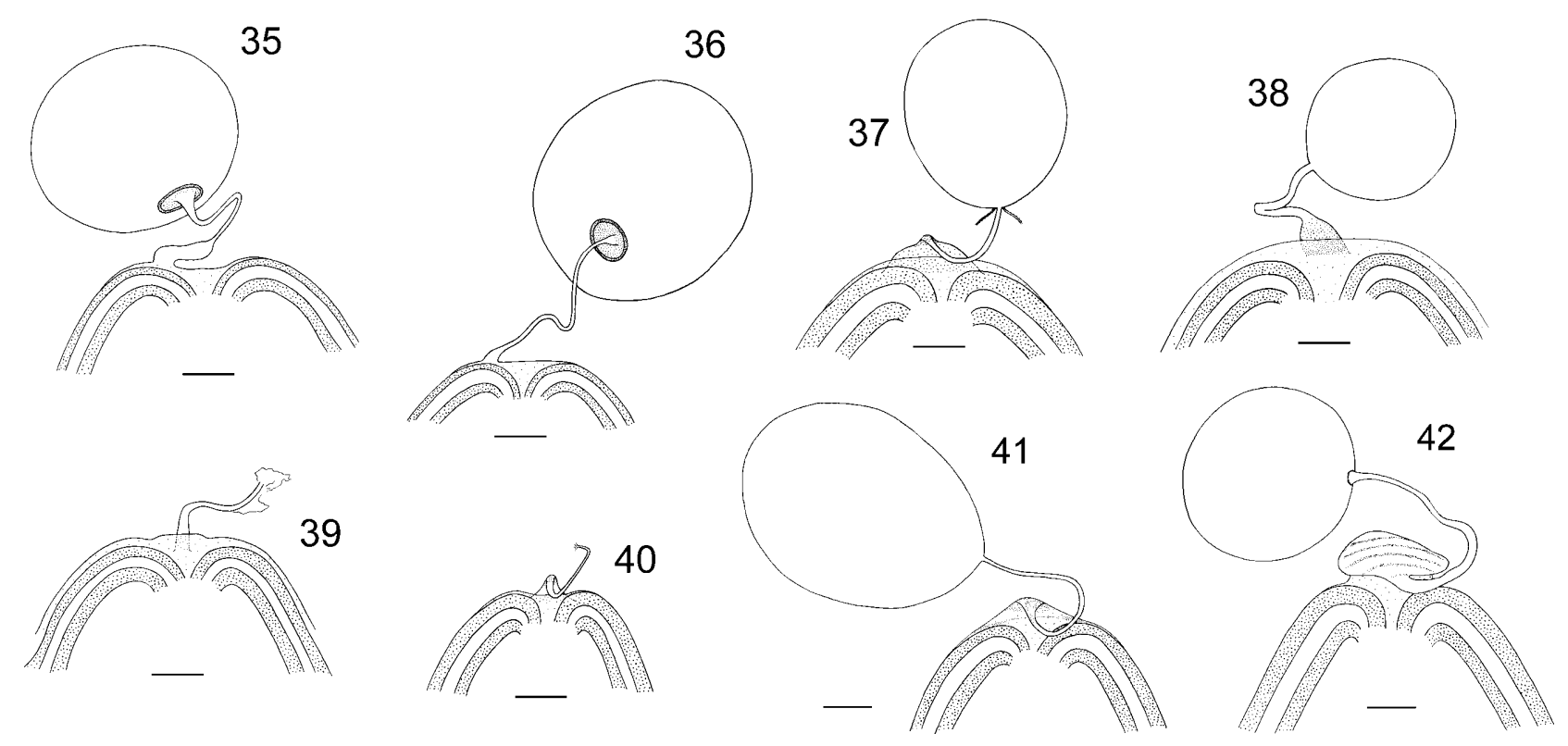

Figs 35-42: Copulatory tubes of Anthocoris spp. 35 - A. sibiricus; 36 - A. tomentosus; 37 - A. armatus; 38 - A. atricornis; 39 - A. dimorphus; $40-A$. hirsutus; $41-A$. hsiaoi; $42-$ A. thibetanus. Scale $=0.1 \mathrm{~mm}$.

\section{A. butleri (Fig. 27)}

Duct length $1.2 \mathrm{~mm}$; basal part irregularly cystiform; wall of subapical $1 / 8$ a little thinner, densely covered with rough transverse rugosities; apical part entering into the sac and connecting with its internal gourd-shaped vesicle.

\section{A. nemoralis (Fig. 28)}

Duct length $1.2 \mathrm{~mm}$; basal part regularly cystiform, apical part that enters into the sac thickens abruptly, then thins gradually.

\section{A. nemorum type}

Duct attached to left or extreme left of intersegmental membrane between sterna VII and VIII; diameter of whole duct varies a little; usually with a few twists. Sac with wire-like tubules similar as those of A. gallarumulmi type near junction of duct and sac, except sac of $A$. musculus with four tubules congregated into two pairs, other four species with two tubules.

\section{A. antevolens (Fig. 29)}

Duct length $0.7 \mathrm{~mm}$; attached to left of lower surface of intersegmental membrane.

\section{A. limbatus (Fig. 30)}

Intersegmental membrane with an apophysis near middle of edge. Duct length $0.5 \mathrm{~mm}$; attached to left lower surface of intersegmental membrane; apical $1 / 6$ sclerotized, slightly enters into the sac.

\section{A. montanus (Fig. 31)}

Intersegmental membrane with small apophysis in middle of edge. Duct length $0.7 \mathrm{~mm}$; attached to extreme left of lower surface of intersegmental membrane; whole duct with fine transverse rugosities on the wall; apical 1/6 sclerotized, most of the sclerotized part enters into the sac.

\section{A. musculus (Fig. 32)}

Duct length $0.5 \mathrm{~mm}$; attached to left of lower surface of intersegmental membrane; thins slightly and gradually to apex; basal $1 / 2$ with fine transverse rugosities on wall; apical $1 / 2$ without rugosity.

\section{A. nemorum (Fig. 33)}

Duct thin, length $0.6 \mathrm{~mm}$; attached to left of upper surface of intersegmental membrane; whole duct with fine transverse rugosities on wall; apical 2/7 sclerotized; 2/3 of sclerotized part enters into the sac, bent slightly.

\section{A. sibiricus type}

Whole duct short; attached to left edge of intersegmental membrane between sterna VII and VIII; duct thin except basal and apical parts; basal part dilated; apical part widens gradually, campaniform or speaker-like. Sac with a strongly sclerotized annular structure encircling junction of duct and sac; wall of the sac within the annular structure thickened.

\section{A. pilosus (Fig. 34)}

Duct length $0.5 \mathrm{~mm}$; basal $1 / 5$ extends to the right horizontally, about 3 times as thick as middle $3 / 5$, then duct narrows; apical $1 / 5$ speaker-like.

\section{A. sibiricus (Fig. 35)}

Duct length $0.4 \mathrm{~mm}$; basal $1 / 3$ extends to the right horizontally; 4 times as thick as middle $1 / 2$; apical $1 / 6$ speaker-like.

The copulatory tubes are very similar in A. sibiricus and A. pilosus, but they are differing in the degree of dilation of basal part and proportion of dilated basal part compared to the whole length of the duct.

Péricart (1972) considered A. pilosus to be a junior synonym of A. sibiricus. Elov \& Kerzhner (1977) retained their species levels. The differences in the copu- 
latory tubes between these two species in our study also indicates that they are different species.

\section{A. tomentosus (Fig. 36)}

Duct length $0.4 \mathrm{~mm}$; basal 1/10 dilated, about 2.5 times thickness of middle $4 / 5$; apical $1 / 10$ thickened, campaniform.

\section{A. thibetanus type}

Whole duct short; attached to middle or middle edge of intersegmental membrane between sterna VII and VIII; basal part usually dilats into various shapes.

\section{A. armatus (Fig. 37)}

Duct length $0.3 \mathrm{~mm}$; attached to the middle of lower surface of intersegmental membrane; basal part expanded extremely, forms a flat, approximately semi-circled structure; the rest thin; diameter of duct except basal part hardly varies. Sac with two tubules near the junction of duct and sac.

\section{A. atricornis (Fig. 38)}

Duct length $0.4 \mathrm{~mm}$; attached to middle of lower surface of intersegmental membrane; basal part dilated apparently, forms a flat, shovel-like structure, about 4 times as wide as middle part; diameter of duct constant except for basal part.

\section{A. dimorphus (Fig. 39)}

Duct length $0.3 \mathrm{~mm}$; attached to middle of lower surface of intersegmental membrane; basal half thicker than apical half, thins gradually from base to middle; apical half with same diameter, about 1/2 times as thick as base.

We only saw a trace of the sac at the end of duct in a few specimens (including paratypes) examined. The sac probably broke off during the dissection.

\section{A. hirsutus (Fig. 40)}

Duct length $0.3 \mathrm{~mm}$; attached to middle of lower surface of intersegmental membrane; basal part dilated apparently, forms an acute triangular, sheet-like structure; sub-basal to middle thins gradually, generally thicker than apical half, apical half thin with same diameter.

We only saw a trace of sac at the end of duct in the specimens dissected. The sac probably broke off during the dissection.

\section{A. hsiaoi (Fig. 41)}

Duct length $0.5 \mathrm{~mm}$; attached to middle edge of intersegmental membrane; basal part dilated apparently, forms an obtuse triangle; whole duct except basal part thin with same diameter.

\section{A. thibetanus (Fig. 42)}

Duct length $0.7 \mathrm{~mm}$; attached to middle edge of intersegmental membrane; basal part greatly expanded, irregular, vesica-shaped with many rough rugosities, alternated between dark and pale stripes on wall; base of tubular part extended rightward from the middle of the vesicashaped structure, then thins gradually to subapex; apical part thickened slightly, connected to the sac by a sclerotized annular structure.

\section{ANALYSIS}

In the ten types of copulatory tubes of Anthocoris, A. alpinus type is probably the plesiomorphic form, but it is hard to determine how it had been transformed into the other types. The homologous characters of the ten types of copulatory tubes described above, however, show the following transformations.

\section{Duct}

I. Basal part: tubular, not dilated - 0; tubular, dilated 1 ; cystiform -2 .

II. Middle part: tubular, neither thick or thin -0 ; with abrupt dilation -1 ; more or less spoon-like -2 .

III. Apical part: neither thick or thin - 0; widening slightly -1 ; widening -2 ; narrowing slightly -3 ; wirelike -4 .

IV. Texture of the apical duct wall: not sclerotized -0 ; sclerotized -1 .

V. Junction between duct and sac: connects directly 0 ; enters into sac, apex open - 1; enters into the sac, apex connected with a vesicle -2 .

\section{Sac}

VI. Near the junction of duct and sac: without any particular structures - 0; membrane thickened - 1; with a sclerotized annular structure - 2; with pairs of short tubules -3 .

The distribution of the six characters in the ten types of copulatory tubes is summarized in Table 1 .

TABLE 1. Distribution of six characters in the ten types of copulatory tubes.

\begin{tabular}{lcccccc}
\hline Types characters & I & II & III & IV & V & VI \\
\hline A. albiger type & 0 & 1 & 0,1 & 1 & 1 & 0 \\
A. alpinus type & 0 & 0 & 0,3 & 1 & 1 & 0 \\
A. chibi type & 1 & 0 & 1 & 1 & 0 & 1,2 \\
A. fulvipennis type & 0,1 & 2 & 1,3 & 1 & 0 & $0,1,3$ \\
A. gallarumulmi type & 0,1 & 0 & 0,1 & 1 & $0,1,2$ & $0,1,3$ \\
A. miyamotoi type & 1 & 0 & 4 & 1 & 0 & 0 \\
A. nemoralis type & 2 & 0 & 1,2 & 1 & 1,2 & 0 \\
A. nemorum type & 0 & 0 & 0,1 & 0,1 & 0,1 & 3 \\
A. sibiricus type & 1 & 0 & 1,2 & 0 & 0 & 1,2 \\
A. thibetanus type & 1,2 & 0 & 0,1 & 0 & 0 & $0,2,3$ \\
\hline
\end{tabular}

\section{CONCLUSIONS}

1. The structures of the female copulatory tubes of the genus Anthocoris vary between species, but are stable within a species, suggesting they may be of use in identifying females at species level.

2. The copulatory tubes of the forty species can be divided into ten types, and employed for subdivision of the genus Anthocoris.

3. The copulatory tubes are useful for the phylogenetic study of the genus.

\section{SUBDIVISION OF THE GENUS ANTHOCORIS}

The subdivision of the genus Anthocoris is poorly studied on a worldwide scale. Hill (1957) divided the six 
North American species into three groups according to body form, color and male genitalia. Péricart (1972) investigated Anthocoridae of the West Palaearctic region, and grouped fifteen species into six groups and one particular species based on characters of the fore wing, sternum II of the abdomen and male genitalia. Accepting Péricart (1972)'s groups and adding more species, Bu \& Zheng (2001) grouped thirty-seven species from China into nine groups. The above three papers dealt with a total of fifty-two species.

Using body form, color pattern, luster and pubescence of fore wing, morphology of sternum II and III of abdomen, male genitalia, and the female copulatory tubes of forty species, of which thirty-six species had been considered previously, four species from North America, fifty-six species from the Holarctic region, northern parts of the Oriental and Neotropical regions were divided into thirteen groups.

A comparison of the species grouping in the present paper and the former three papers is shown in the following table (Table 2). For clarity, previous groups are placed in the groups adopted here.

Compared with the former species groupings, we studied more species from more regions and used copulatory tubes to determine our species grouping. Here, seven groups are consistent with the previous groupings. Due to the lack of specimens of the alienus group of Péricart (1972), and unsuccessful dissection of specimens from the angustatus group of Bu \& Zheng (2001), we retained these two groups. Combination and rearrangement of previous groups and addition of a new one resulted in the following subdivision of Anthocoris:

\section{A. albiger group}

Body slender. Pubescence on hemelytron relatively dense, decumbent or semi-erect. Clavus and inner portion of endocorium dull; outer portion of endocorium, exocorium and cuneus shiny. Sternum II or III of abdomen without membranous area. Paramere lamellate, without longitudinal groove. Copulatory tube of $A$. albiger type. Western and southwestern areas of North America; two species: A. albiger Reuter, 1884 and A. whitei Reuter, 1884.

\section{A. alienus group}

Body relatively narrow and elongate. Clavus more or less dull brown; corium and cuneus shiny. Sternum II of abdomen with a pair of membranous areas. Paramere lamellate, without longitudinal groove, with an obtuse dentation at inner margin. Copulatory tube has never been studied. Western Palaearctic region. Two species: $A$. alienus (White, 1880) and A. salicis Lindberg, 1953.

\section{A. angustatus group}

Body relatively narrow and elongate. Callar area strongly swollen, post-callar depression deep. Hemelytron shiny, with relatively long, sparse pubescence. Sternum II of abdomen with a pair of kidney-shaped membranous areas. Paramere lamellate, long and narrow, curved, without longitudinal groove. Copulatory tube has never been successfully dissected. The western and southwestern areas of China, six species: A. angustatus Zheng, 1984, A. concinnus Bu \& Zheng, 1991, A. gracilis Zheng, 1984, A. hiurai Bu \& Zheng, 2001, A. yangi Bu \& Zheng, 1991 and $A$. zhengi Péricart, 1996.

\section{A. chibi group}

Body relatively small, elongately oval. Pubescence on hemelytron mostly decumbent, with a few erect or semierect hairs, more or less curved. Clavus and endocorium dull, with silvery white pubescence; exocorium and cuneus strongly shiny, with golden brown pubescence. Sternum II of abdomen with a pair of kidney-shaped membranous areas. Paramere slender, most of outer margin reflexed, apical portion slightly curving inward. Copulatory tube of $A$. chibi type. The eastern part of Asia, two species: A. chibi Hiura, 1959 and A. notatotibialis $\mathrm{Bu}$ \& Zheng, 2001.

\section{A. confusus group}

Body elongately oval. Pubescence on hemelytron semierect. Clavus, inner portion or the whole endocorium dull, sometimes inner portion of exocorium also dull. Sternum II of abdomen with a pair of membranous areas. Paramere

TABLE 2. Comparisons of the four suggested groupings of Anthocoris.

\begin{tabular}{|c|c|c|c|}
\hline Suggested groups in this paper & Hill (1957) & Péricart (1972) & Bu \& Zheng (2001) \\
\hline A. albiger group & Group III & & \\
\hline A. alienus group & & alienus group & \\
\hline A. angustatus group & & & angustatus group \\
\hline A. chibi group & & & chibi group \\
\hline A. confusus group & & confusus group & confusus group \\
\hline A. flavipes group & & a particular species $A$. flavipes & flavipes group \\
\hline \multicolumn{4}{|l|}{ A. fulvipennis group } \\
\hline A. gallarumulmi group & A. bakeri of Group II & gallarumulmi group & japonicus group \\
\hline A. miyamotoi group & & & miyamotoi group \\
\hline A. nemoralis group & & nemoralis group & \\
\hline A. nemorum group & Group I & nemorum group & nemorum group \\
\hline A. sibiricus group & A. tomentosus of Group II & sibiricus group & sibiricus group \\
\hline A. thibetanus group & & & thibetanus group \\
\hline
\end{tabular}


lamellate, without longitudinal groove, with a dentation at inner margin of sub-apex. Copulatory tube of A. gallarumulmi type. Five species, A. confusus Reuter, 1884, A. minki Dohrn, 1860, A. sarothamni Douglas \& Scott, 1865, A. simulans Reuter, 1884 and A. visci Douglas, 1889; four of them in the Palaearctic, only $A$. confusus extensively in the Holarctic.

\section{A. flavipes group}

Body relatively narrow and elongate. Hemelytron dull fulvous to dark brown, with long, semi-erect pubescence. Sternum II or III of abdomen without membranous area. Paramere lamellate, long and narrow, angular, without longitudinal groove. Copulatory tube of $A$. thibetanus type. Eastern and central Palaearctic; three species: $A$. armatus Bu \& Zheng, 1991, A. flavipes Reuter, 1884 and A. longiusculus $\mathrm{Bu} \&$ Zheng, 1991.

\section{A. fulvipennis group}

Body elongate. Pubescence on hemelytron relatively sparse, glittering silvery, decumbent. Surface of hemelytron coarse, dull fulvous to dull rufous. Sternum II or III of abdomen without membranous area. Paramere lamellate, without longitudinal groove, narrowed abruptly at apex forming a sharp angle. Copulatory tube of $A$. fulvipennis type. Western and southwestern parts of North America; four species: A. fulvipennis Reuter, 1884, A. nigripes Reuter, 1884, A. rufotinctus Champion, 1900 and $A$. variipes Champion, 1900.

\section{A. gallarumulmi group}

Body elongately oval. Clavus, inner portion or the whole endocorium dull fulvous to dull brown, not shiny, sometimes inner portion of exocorium also dull. Sternum II of abdomen with a pair of membranous areas. Paramere lamellate, clearly curved inward at sub-apex, without longitudinal groove. Copulatory tube of A. gallarumulmi type. Six species, A. amplicollis Horváth, 1893, A. bakeri Poppius, 1913, A. gallarumulmi (De Geer, 1773), A. japonicus Poppius, 1909, A. takahashii Hiura, 1959 and A. ussuriensis Lindberg, 1927, three are found in the eastern and central parts of Asia. A. gallarumulmi and $A$. amplicollis in Europe and the western part of Asia, $A$. bakeri in western North America.

\section{A. miyamotoi group}

Body narrowly elongate. Callar area relatively extensive and strongly swollen, post-callar depression deep; posterior lobe of pronotum smooth, not rugulose. Hemelytron shiny, with long, sparse pubescence; outer part of median portion in clavus and endocorium, median portion of exocorium, areas around cuneal suture light in color and transparent; other areas of hemelytron shiny, blackish brown. Sternum III of abdomen with a pair of kidneyshaped membranous areas. Paramere lamellate or sinuate, without longitudinal groove. Copulatory tube of $A$. miyamotoi type. Eastern part of Asia; two species: A. dividens Bu \& Zheng, 2001 and A. miyamotoi Hiura, 1959.

\section{A. nemoralis group}

Body elongately oval. Pubescence on hemelytron relatively dense, long, semi-erect. Clavus and endocorium dull; exocorium and cuneus shiny. Sternum II of abdomen with a pair of membranous areas. Paramere slender, curved, without longitudinal groove. Copulatory tube of A. nemoralis type. Two species: A. butleri Le Quesne, 1954 from the western Palaearctic and A. nemoralis (Fabricius, 1794) from the Holarctic.

\section{A. nemorum group}

Body elongately oval. Hemelytron shining, with short, relatively decumbent pubescence. Basal half or the whole endocorium light-colored. Sternum II or III of abdomen without membranous area. Paramere lamellate, outer portion expanded outward, forming a longitudinal groove. Copulatory tube of $A$. nemorum or $A$. alpinus type. Eleven species, $A$. alpinus Zheng, 1984, A. antevolens White, 1879, A. expansus Bu, 1995, A. kerzhneri $\mathrm{Bu} \&$ Zheng, 2001, A. limbatus Fieber, 1836, A. montanus Zheng, 1984, A. musculus (Say, 1832), A. nemorum (Linnaeus, 1761), A. pericarti Bu \& Zheng, 2001, A. qinlingensis Bu \& Zheng, 1990 and A. zoui Bu \& Zheng, 2001; nine of them in the Palaearctic. A. musculus is in the Nearctic, and $A$. antevolens in the Nearctic and the northern part of the Neotropical region.

\section{A. sibiricus group}

Body elongately oval. Pubescence on hemelytron relatively long, decumbent or semi-erect. Surface of hemelytron shiny, apex of clavus, corium, and cuneus always dark. Sternum II of abdomen with a transverse, relatively long and narrow membranous area. Paramere long and narrow, lamellate, curved inward at apex, without longitudinal groove. Copulatory tube of $A$. sibiricus type. Four species, A. marginatus Zheng, 1982, A. pilosus (Jakovlev, 1877), A. sibiricus Reuter, 1875 and A. tomentosus Péricart, 1971; three in the Palaearctic, A. tomentosus is in the Nearctic.

\section{A. thibetanus group}

Body elongately oval. Hemelytron shining, with long, dense, erect or semi-erect pubescence. Basal half of exocorium light-colored, other areas of hemelytron dark brown to blackish brown. Sternum II or III of abdomen without membranous area. Paramere long and narrow, curved or angular, without longitudinal groove. Copulatory tube of $A$. thibetanus type. Western and southwestern China; seven species: A ailaoanus Bu \& Zheng, 1991, A. atricornis Bu \& Zheng, 1991, A. dimorphus Zheng, 1984, A. hirsutus Zheng, 1982, A. hsiaoi Bu \& Zheng, 1991, A. thibetanus Poppius, 1909 and A. yunnanus Zheng, 1984.

The new grouping proposed here includes about eighty percent of the species of Anthocoris. Due to the lack of specimens, 15 species were not studied: $A$. annulipes Poppius, 1909, A. excelsus Péricart, 1987 and A. indicus Poppius, 1909 (Oriental region); A. angularis Reuter, 1884, A. caucasicus Kolenati, 1857, A. kalopanacis Kerzhner, 1976, A. poissoni Kiritshenko, 1952 and $A$. simillimus Poppius, 1909 (Palaearctic region); A. dimor- 
phicus Anderson \& Kelton, 1963 and A. tristis Van Duzee, 1921 (Nearctic region); A. dentipes Champion, 1900 and $A$. variicornis Champion, 1900 (Neotropical region); A. austropiceus Gross, 1954 and A. pacificus Kirkaldy, 1908 (Australian region); A. nitidulus Poppius, 1920 (Afrotropical region).

ACKNOWLEDGEMENTS. We thank L. Zheng and J. Zhou (Nankai University, Tianjin, China), P. Štys (Charles University, Prague, Czech Rep.) and anonymous reviewers for their reviews on the manuscript. We are grateful to J. Péricart (Montereau, France) for his valuable suggestion on the taxonomy of Anthocoris, We also would like to thank the following people and institutions, without whose assistance, we could not have completed this work, R.T. Schuh, American Museum of Natural History, New York, USA; W.R. Dolling, The Natural History Museum, London, UK; W.Y. Chen, Section of Entomology, Carnegie Museum of Natural History, Pittsburgh, Pennsylvania, USA; J.S. Ashe, Entomological Division, Natural History Museum, University of Kansas, Kansas, USA. The project was supported by National Natural Sciences Foundation of China (No. 30570192) and the National Cultivation Project of Special Subjects in Basic Science (Insect Taxonomy, 2002-2006) of National Natural Sciences Foundation of China.

\section{REFERENCES}

Bu W.J. \& Zheng L.Y. 2001: Fauna Sinica. Insecta Vol. 24 (Hemiptera: Lasiochilidae, Lyctocoridae, Anthocoridae). Science Press, Beijing, $267 \mathrm{pp}$.

CARAYON J. 1953: Existence d'un double orifice genital et d'un tissu conducteur des spermatozoides chez les Anthocorinae (Hemiptera: Anthocoridae). C. R. Acad. Sci. Fr. 236: 12061208.

Carayon J. 1956: Anthocoridae Scolopini nouvaeux d'Afrique tropicale (Hemiptera, Heteroptera). Bull. Mus. Hist. Nat. Paris 28: 183-190.

CARAYON J. 1957: Introduction à l'etude des Anthocoridae omphalophores (Hemiptera, Heteroptera). Ann. Soc. Entomol. Fr. 126: 159-197.

Carayon J. 1961: Hemiptera (Heteroptera): Anthocoridae. $S$ Afric. Anim. Life 8: 533-557.

CARAYON J. 1972: Caractères systématiques et classification des Anthocoridae (Hemiptera). Ann. Soc. Entomol. Fr. 8: 309-349.
Carpintero D.L. 2002: Catalogue of the Neotropical Anthocoridae (Heteroptera). Rev. Soc. Entomol. Argent. 61: 25-44.

Elov E.S. \& KerzhNer I.M. 1977: Bugs of the families of Anthocoridae, Cimicidae and Microphysidae (Heteroptera) of the Mongolian People's Republic. Insects of Mongolia 5: 203-220.

Gross G.F. 1954: A revision of the flower bugs (Heteroptera: Anthocoridae) of the Australian and adjacent regions. Rec. S. Aust. Mus. 11: 133-136.

Henry T.J. \& Froeschner R.C. 1988: Catalogue of the Heteroptera, or True Bugs, of Canada and the Continental United States. Brill, Leiden, New York, pp. 12-28, xvii.

HeRnÁNDEZ L.M. \& Stonedahl G.M. 1999: A review of the economically important species of the genus Orius (Heteroptera: Anthocoridae) in East Africa. J. Nat. His. 33: 543-568.

HiLl A.R. 1957: A key to the North American members of the genus Anthocoris Fallén (Hemiptera: Anthocoridae). PanPacif. Entomol. 33(4): 171-174.

KE Y.L. \& Bu W.J. 2005: A morphological study on female copulatory tubes of the genus Tetraphleps Fieber (Hemiptera: Heteroptera: Anthocoridae) from China. Act. Entomol. Sin. 48: 391-395.

MuraleEdHaran N. \& Ananthakrishnan T.N. 1978: Bioecology of four species of Anthocoridae (Insecta: Hemiptera) predaceous on thrips, with key to genera of anthocorids from India. Rec. Zool. Surv. India 11: 1-32.

PÉrICART J. 1972: Hémiptères Anthocoridae, Cimicidae et Microphysidae de l'Ouest-Palearctique. In Faune de l'Europe et du Bassin Méditerranéen 7. Masson et Cie, Paris, pp. $1-190$.

PÉrICART J. 1996: Family Anthocoridae Fieber, 1836 - flower bugs, minute pirate bugs. In Aukema B. \& Rieger C. (eds): Catalogue of the Heteroptera of the Palaearctic Region. Vol. 2. The Netherlands Entomological Society, Amsterdam, pp. 108-140, xi-xii.

Postle A.C., Steiner M.Y. \& Goodwin S. 2001: Oriini (Hemiptera: Anthocoridae) new to Australia. Aust. J. Entomol. 40: 231-244.

Yasunaga T. 1997: The flower bug genus Orius Wolff (Heteroptera: Anthocoridae) from Japan and Taiwan, Part I, II, III. Appl. Entomol. Zool. 32: 355-364, 379-386, 387-394.

YasunaGa T. 2000: Anthocorid bugs of the tribe Oriini (Heteroptera: Anthocoridae) of the Ogasawara (Bonin) Islands, Japan. Proc. Entomol. Soc. Wash. 102: 353-359.

Received November 18, 2005; revised and accepted May 10, 2006 